\title{
Effect of Steroid during Perioperative Period in Patients with Patent Ductus Arteriosus (PDA) Ligation
}

\author{
Kazi Zahidul Hoque, ${ }^{1}$ Masumul Gani Chowdhury, ${ }^{2}$ Mamun Miah, ${ }^{3}$ Akhand Tanzih Sultana ${ }^{4}$
}

\begin{abstract}
Background \& Objective: Patent ductus arteriosus (PDA) is a common condition in preterm infants and is associated with profound morbidity and mortality. Pharmacotherapy (indomethacin or ibuprofen) is the first choice to close the PDA, but if pharmacological closure is contraindicated or failed, surgical ligation is usually performed. But following surgical ligation of PDA, preterm infants may develop severe hypotension and respiratory failure. Prophylactic stress hydrocortisone (HC) has emerged as a therapy to prevent complications, although its efficacy in reducing postoperative hypotension and oxygenation difficulties has not been rigorously tested. The purpose of this study was to compare the outcomes in preterm infants who received stress $\mathrm{HC}$ before their PDA ligation to those who did not (standard treatment group or control).

Materials \& Methods: This comparative clinical trial was conducted in Dhaka Shishu Hospital (DSH), Dhaka over a period of 15 months between April 2014 to June 2015. A total of 40 infants with a significant PDA and a history of failed medical treatment were included in the study and were divided into two groups (each group having 20 infants) - one receiving stress HC before PDA ligation (Case) and the other did not (Control). Respiratory support, expressed as highest FiO2, highest mean airway pressure and mode of ventilation, was noted as was cardiovascular support including inotropic medication, its dose throughout the preoperative and the postoperative periods. Post-operative cardiovascular and respiratory supports were the main outcome measures which were measured within 72 hours following PDA ligation.

Result: At baseline both the study groups were almost similar with respect to their sex, gestational age, birth weight, and age at surgery and prenatal steroid exposure. However, there was more incidence of preoperative steroid exposure in standard treatment group. Urine output was somewhat higher in the standard treatment group compared to the HC group but it was not statistically significant (1.33 vs. $1.21 \mathrm{ml} / \mathrm{kg} / \mathrm{min}, \mathrm{p}=0.205)$. The mean arterial pressure was higher in the $\mathrm{HC}$ group than that in the standard treatment group ( $92.5 \mathrm{vs} .86 .7$ $\mathrm{mmHg}, \mathrm{p}=0.018$ ), but it was clinically insignificant. The study observed that infants who received stress dose $\mathrm{HC}$ rarely needed vasopressor support post ligation and their average and highest doses of dopamine were also significantly lower compared to their standard treatment group. The postoperative high-frequency ventilation was more often needed in the standard treatment group, although none in either group needed this support preoperatively. The mean airway pressure was although similar in both groups the highest FiO2 was much less in the HC group.
\end{abstract}

Conclusion: The study concluded that stress dose HC given to preterm infants before surgical ligation of PDA may improve the postoperative cardiorespiratory outcomes. But as the sample size was too small, this finding requires validation by large-scale study.

Key words: Patent ductus arteriosus (PDA), stress dose hydrocortisone, postoperative cardiorespiratory outcomes.

\section{Authors' information:}

Dr. Kazi Zahidul Hoque, Assistant Professor, Paediatric Cardiac Surgery, Dhaka Shishu (Children) Hospital, Dhaka. 2 Dr. Masumul Gani Chowdhury, Assistant Professor, Paediatric Cardiac Surgery, Dhaka Shishu (Children) Hospital, Dhaka.

${ }^{3}$ Dr. Mamun Miah, Assistant Professor, Department of Paediatric Rheumatology, Bangladesh Institute of Child Health (BICH), Dhaka Shishu (Children) Hospital.

${ }^{4}$ Dr. Akhand Tanzih Sultana, Assistant Professor, Department of Paediatric Pulmonology, Bangladesh Institute of Child Health (BICH), Dhaka Shishu (Children) Hospital.

Correspondence: Dr. Kazi Zahidul Hoque, Cell phone: +880 1711-352549, E-mail: kzhoqu72@yahoo.com. 


\section{INTRODUCTION}

Patent ductus arteriosus (PDA) is the persistent patency of the ductus arteriosus (an essential fetal vascular structure that connects the proximal descending aorta to the pulmonary artery roof, near the origin of the left branch) after the neonatal period. ${ }^{1}$ It is a common condition in infants and is associated with considerable mortality and morbidity. ${ }^{2,3}$ Significant left-to-right shunt through PDA can cause respiratory distress, cardiac failure, hypotension and a decrease in perfusion and oxygen delivery to end-organs. ${ }^{4,5}$ Over three decades of research and clinical trials have established 3 different approaches for management of PDA: conservative management with supportive therapy alone, pharmacologic closure using cyclooxygenase inhibitors (indomethacin or ibuprofen or more recently, acetaminophen) and surgical ligation ${ }^{6}$ aimed at mitigating the potential negative effects of the ductal shunt. ${ }^{7}$ Prostaglandin inhibitors, such as indomethacin or ibuprofen, are used to close the PDA, but if pharmacological closure is contraindicated due to bleeding diathesis, necrotizing enterocolitis (NEC) or where nonsteroidal anti-inflammatory drugs (NSAIDs) are contraindicated or unsuccessful, surgical ligation is usually performed in most cases according to present clinical practice. ${ }^{8}$ Surgery is well-tolerated in most infants, but 30\% may develop severe systemic hypotension and respiratory decline requiring maximum levels of cardiopulmonary support in the postoperative period. $^{9}$

Developmental immaturity of the hypothalamicpituitary-adrenal axis in extremely premature infants may have a role in preventing these infants from mounting an adequate response to stress or illness. ${ }^{8}$ It has been well documented that stress hydrocortisone $(\mathrm{HC})$ can be used to treat vasopressor-resistant hypotension. ${ }^{10,11}$ Moreover, studies have shown that infants with refractory hypotension have higher blood pressures following a physiological stress dose of $\mathrm{HC}$ as well as improved urine output. ${ }^{12}$ Although surgical ligation of a persistent patent ductus arteriosus resolves the adverse hemodynamic consequences of the systemic-to-pulmonary shunt and may confer some long-term benefits, it is also associated with both immediate and long-term negative effects. The population that benefits from or is harmed by the procedure is not clearly defined. ${ }^{13}$ Whether a prophylactic stress dose of $\mathrm{HC}$ before PDA ligation can prevent postoperative hypotension and oxygenation difficulties has not yet been investigated. Despite this, use of stress dose HC preoperatively has crept into practice. That purpose the present study was intended to compare the outcomes between infants who received stress $\mathrm{HC}$ before their PDA ligation and those who did not.

\section{MATERIALS AND METHODS}

This comparative clinical trial was conducted in Dhaka Shishu Hospital (DSH), Dhaka over a period of 15 months between April 2014 to June 2015. Infants admitted with a significant PDA and had a history of failed medical treatment despite two courses of Ibuprofen or beyond 4 weeks of age when ibuprofen may be less effective for PDA. An 'echocardiographically significant' PDA was defined if the ductal diameter was $\geq 2.0 \mathrm{~mm}$, had a pulsatile ductal flow pattern, LA: Aortic root ratio $\geq 1.5$, retrograde post-ductal aortic diastolic flow and abnormal diastolic mesenteric or cerebral flow. The presence of 2 or more of these features justified the presence of significant PDA.

A total 40 infants with a significant PDA and a history of failed medical treatment were included in the study and were dived into two groups (each group having 20 infants) - one receiving stress $\mathrm{HC}$ before PDA ligation (Case) and the other did not (Control or standard treatment group). The ligations were performed by senior pediatric cardiothoracic surgeons in the operating room. Use of HC, vasopressors and ventilatory support was at the discretion of the attending physician. Data were collected on preoperative $24 \mathrm{~h}$, as an indicator of baseline stability, and the postoperative $72 \mathrm{~h}$ after PDA ligation. Information about $\mathrm{HC}$ administration including dosage and duration of therapy was noted. Respiratory support expressed as highest FiO2, highest mean 
airway pressure and mode of ventilation was collected as was cardiovascular support including inotropic medication and its dose throughout the preoperative and the postoperative periods. Inotropic medication administration was at the discretion of the physician caring for the patients. However, most physicians at our institution followed a guideline which states that inotropic support should be provided if the mean arterial pressure (MAP) is $<30 \mathrm{mmHg}$. Post-operative cardiovascular and respiratory support was the main outcome measures. Infants' demographics including birth weight (BW), gestational age (GA), age at time of the surgery, prenatal steroid exposure and urine output as a measure of perfusion were collected. Hospital outcomes included events from PDA ligation to discharge. Results are shown as median and standard error of mean (SEM) for the continuous variables, and frequency (percentage) for the categorical variables. The continuous variables were compared between groups using Mann Whitney $U$ test (as the data were not normally distributed), while categorical variables between groups were compared employing Fisher's Exact Test. Analyses were done using software SPSS (Statistical Package for Social Sciences), version 17. The level of significance was set at 0.05 and $p<0.05$ was considered significant.

\section{RESULTS}

Demographic and baseline characteristics of the patients are presented in table I. There was no significant difference between case and control groups in terms of gestational age, birth weight and age at surgery, sex and prenatal exposure to steroid $(p>0.05)$. Six patients $(30 \%)$ in the case group and 10 patients in the control group (50\%) were already on steroid therapy for refractory hypotension ( $p=0.137)$. The average urine output in the case group was $1.33 \mathrm{ml} / \mathrm{kg} / \mathrm{min}$ as compared to $1.21 \mathrm{ml} / \mathrm{kg} / \mathrm{min}$ in the control group $(p=0.205)$. The mean arterial systolic pressure $(\mathrm{mmHg})$ was significantly higher in the former group than that in the latter group (0.018). However, mean arterial diastolic pressure was no different between groups ( $p=0.294)$. Treatment with inotropic medication at baseline shows that dopamine therapy and average dopamine dose were almost identically received by the case and control groups $(p=0.247$ and $p=0.354$ respectively). Dobutamine and epinephrine were not at all used in either of the groups (Table I). Majority $(90 \%)$ of the neonates in the case group was ventilated with extubation method. The highest mean airway pressure was almost identical between groups ( $p=0.430)$ (Table II).

Outcome of the study demonstrates that the infants needing postoperative dopamine therapy was considerably less $(10 \%)$ in case group than that in control group $(35 \%)(p=0.064)$. The case group required much lower dose of dopamine (3.3 $\mu \mathrm{g} / \mathrm{kg} / \mathrm{min}$ ) than the control group (5.9 $\mu \mathrm{g} / \mathrm{kg} / \mathrm{min})(\mathrm{p}<0.001)$. The highest dose of dopamine was also much lower in infants receiving stress dose of $\mathrm{HC}(4.0 \mu \mathrm{g} / \mathrm{kg} / \mathrm{min})$ than those without stress dose of $\mathrm{HC}(6.55 \mu \mathrm{g} / \mathrm{kg} / \mathrm{min})$ ( $\mathrm{p}<$ $0.001)$. None of the infants in the former group needed dubotamine as compared to $2(10 \%)$ in the latter group $(p=0.487)$.

\begin{tabular}{|c|c|c|c|}
\hline \multicolumn{4}{|c|}{$\begin{array}{l}\text { TABLE I. Comparison of demograp hic \& baseline } \\
\text { characteristics between groups }\end{array}$} \\
\hline \multirow{2}{*}{$\begin{array}{l}\text { Demographic } \& \text { baseline } \\
\text { characteristics }\end{array}$} & \multicolumn{2}{|c|}{ Group } & \multirow[b]{2}{*}{ p-value } \\
\hline & $\begin{array}{l}\text { Case } \\
(n=20)\end{array}$ & $\begin{array}{l}\text { Control } \\
(n=20)\end{array}$ & \\
\hline Gestational age (week)** & $37.9 \pm 2.3$ & $37.2 \pm 2.4$ & 0.744 \\
\hline Birth weight $(\mathbf{k g})^{* *}$ & $5.7 \pm 1.5$ & $5.3 \pm 1.6$ & 0.913 \\
\hline Age at surgery (months) ${ }^{* *}$ & $5.8 \pm 1.9$ & $5.4 \pm 1.7$ & 0.540 \\
\hline \multicolumn{4}{|l|}{ Sex* } \\
\hline Male & $4(20.0)$ & $6(30.0)$ & \multirow[b]{2}{*}{0.465} \\
\hline Female & $16(80.0)$ & $14(70.0)$ & \\
\hline Prenatal steroid exposure* & $6(30.0)$ & $10(50.0)$ & 0.137 \\
\hline Baseline steroids* & $4(20.0)$ & $12(60.0)$ & 0.010 \\
\hline Urine output** $(\mathrm{ml} / \mathrm{kg} / \mathrm{min})$ & $1.33 \pm 0.41$ & $1.21 \pm 0.12$ & 0.205 \\
\hline Mean arterial systolic pressure ${ }^{* *}(\mathrm{mmHg})$ & $92.5 \pm 8.3$ & $86.7 \pm 6.1$ & 0.018 \\
\hline Mean arterial diastolic pressure ${ }^{* *}(\mathrm{mmHg})$ & $61.5 \pm 11.7$ & $57.7 \pm 10.6$ & 0.294 \\
\hline \multicolumn{4}{|l|}{ Inotropic medications } \\
\hline Dopamine therapy* & $1(5.0)$ & $2(10.0)$ & 0.247 \\
\hline Average dose of dopamine* $(\mu \mathrm{g} / \mathrm{kg} / \mathrm{min})$ & $90.0 \pm 0.0$ & $89.6 \pm 28.9$ & 0.354 \\
\hline
\end{tabular}

*Fisher's Exact Test was done to analyze the data; figures in the parentheses indicate corresponding $\%$.

**Data were analyzed using Mann-Whitney Test and were presented as median \pm Standard Error of Mean (SEM).

The number of infants needing epinephrine was 
also higher in the latter group ( $p=0.465)$. The urine output on $1^{\text {st }} P O D$ increased in both groups compared to their preoperative figures, but it was more so in the case group. None in the case group developed refractory hypotension as opposed to $2(10 \%)$ in the control group ( $p=0.487$ ) (Table III). Seventy percent of the cases required extubation and $30 \%$ conventional mode of ventilation postoperatively, where as in control group $70 \%$ needed extubation, 20\% high frequency and $10 \%$ conventional mode of ventilation. The highest mean airway pressure was no different between the groups $(p=0.305)$. However, the highest FiO2 was significantly lower in the case group than that in the control group ( $p$ $=0.016$ ) (Table IV). Two patients switched from standard treatment to stress HC for refractory hypotension.

TABLE II. Comparison of respiratory support preoperatively between groups

\begin{tabular}{|c|c|c|c|}
\hline \multirow[b]{2}{*}{$\begin{array}{l}\text { Respiratory support } \\
\text { preoperatively }\end{array}$} & \multicolumn{2}{|c|}{ Group } & \multirow[b]{2}{*}{ p-value } \\
\hline & $\begin{array}{l}\text { Case } \\
(n=20)\end{array}$ & $\begin{array}{l}\text { Control } \\
(n=20)\end{array}$ & \\
\hline \multicolumn{4}{|l|}{ Mode of ventilation* } \\
\hline Conventional & $2(10.0)$ & $6(30.0)$ & 0.114 \\
\hline Extubation & $18(90.0)$ & $14(70.0)$ & 0.114 \\
\hline Highest mean airway pressure ${ }^{* *}\left(\mathrm{cmH}_{2} \mathrm{O}\right)$ & $10.1 \pm 3.3$ & $9.5 \pm 2.9$ & 0.430 \\
\hline
\end{tabular}

${ }^{*}$ Fisher's Exact Test was done to analyze the data; figures in the parentheses indicate corresponding \%.

**Data were analyzed using Mann-Whitney Test and were presented as median \pm SEM.

TABLE III. Comparison of postoperative outcome between groups

\begin{tabular}{|c|c|c|c|}
\hline \multirow{2}{*}{$\begin{array}{l}\text { Postoperative cardiovascular } \\
\text { outcome }\end{array}$} & \multicolumn{2}{|c|}{ Group } & \multirow[b]{2}{*}{ p-value } \\
\hline & $\begin{array}{l}\text { Case } \\
(n=20)\end{array}$ & $\begin{array}{l}\text { Control } \\
(n=20)\end{array}$ & \\
\hline Dopan & $2(10.0)$ & $7(35.0)$ & 0.064 \\
\hline ne dose ${ }^{* *}(\mu \mathrm{g} / \mathrm{kg} / \mathrm{min})$ & $3.29 \pm 0.98$ & $5.90 \pm 0.58$ & $<0.001$ \\
\hline Highest dopamine dose** $(\mu \mathrm{g} / \mathrm{kg} / \mathrm{min})$ & $4.00 \pm 1.10$ & $6.55 \pm 0.61$ & $<0.001$ \\
\hline Dobutamine therapy* & $0(0.0)$ & $2(10.0)$ & 0.487 \\
\hline Epinephrine* & $4(20.0)$ & $6(30.0)$ & 0.465 \\
\hline Urine output on $1^{\text {st }} \mathrm{POD}{ }^{* *}(\mathrm{ml} / \mathrm{kg} / \mathrm{min})$ & $1.46 \pm 0.23$ & $1.25 \pm 0.16$ & 0.003 \\
\hline Refractory hypotension* & $0(0.0)$ & $2(10.0)$ & 0.487 \\
\hline
\end{tabular}

*Fisher's Exact Test was done to analyze the data; figures in the parentheses indicate corresponding \%.

${ }^{*}$ Data were analyzed using Mann-Whitney Test and were presented as median \pm SEM.
TABLE IV. Comparison of post ligation respiratory outcomes between groups

\begin{tabular}{lccc} 
Respiratory support & \multicolumn{2}{c}{ Group } & \\
preoperatively & Case & Control & p-value \\
& $(n=20)$ & $(n=20)$ & \\
$\begin{array}{l}\text { Mode of ventilation* } \\
\quad \text { Conventional }\end{array}$ & $6(30.0)$ & $2(10.0)$ & \\
$\quad$ High frequency & $0(0.0)$ & $4(20.0)$ & 0.050 \\
$\quad \begin{array}{l}\text { Extubated } \\
\text { Highest mean airway pressure }\end{array}{ }^{* *}\left(\mathrm{cmH}_{2} 0\right)$ & $9.3 \pm 2.2$ & $9.8 \pm 3.1$ & 0.305 \\
Highest FiO $_{2}{ }^{* *}$ & $31 \pm 6$ & $42 \pm 9$ & 0.016
\end{tabular}

*Fisher's Exact Test was done to analyze the data; figures in the parentheses indicate corresponding \%.

**Data were analyzed using Mann-Whitney Test and were presented as median \pm SEM.

\section{DISCUSSION}

This prospective study was conducted to see whether stress dose $\mathrm{HC}$ given to infants before surgical PDA ligation (baseline) reduced the incidence of postoperative cardiorespiratory instability. The study observed that it has significant favorable outcome. Infants who received stress dose HC rarely needed vasopressor support post ligation and their average and highest doses dopamine were also significantly lower compared to their non-HC counterparts. The postoperative high-frequency ventilation was more frequent in the standard treatment group, although none in either group needed this support preoperatively. The mean airway pressure was although similar in both groups the highest FiO2 was much less in the HC group. Satpute et al. $^{14}$ in a similar study demonstrated that postoperative high-frequency ventilation was more frequent in the standard treatment group than that in the stress dose $\mathrm{HC}$ group; but when adjusted for preoperative support, there was no difference. They concluded that infants on high-frequency ventilation preoperatively were more likely to be on high-frequency ventilation post ligation, regardless of whether or not they received $\mathrm{HC}$.

In the baseline both the study groups were almost alike with respect to their sex, gestational age, birth weight and age at surgery. The prenatal steroid exposure was not significantly different, but there was more incidence of preoperative 
steroid exposure in standard treatment group. Urine output was somewhat higher in the standard treatment group compared to the HC group but it was statistically insignificant (1.33 vs. $1.21 \mathrm{ml} /$ $\mathrm{kg} / \mathrm{min}, \mathrm{p}=0.205)$. The mean arterial pressure was higher in the $\mathrm{HC}$ group than that in the standard treatment group (92.5 vs. $86.7 \mathrm{mmHg}$, $\mathrm{p}=0.018$ ), but it was clinically insignificant. As all the pertinent baseline and clinical characteristics were almost identical between the study groups, the outcome obtained could be attributed to stress dose $\mathrm{HC}$.

Post-operative cardiorespiratory instability in infants is a well-known complication of surgical PDA closure. Frequently these infants require drastically increased levels of cardiac and pulmonary support to maintain cardiopulmonary stability. Even then some infants require prolonged mechanical ventilation, develop chronic lung disease or do not survive to hospital discharge..$^{3,9}$ Although the pathophysiology for this decompensation is not well understood, recent studies have shown the developmentally immature myocardium of infants may not be able to endure abrupt alterations in left ventricular after load, which results from PDA ligation. Left ventricular failure occurs leading to pulmonary edema with difficulty in oxygenation. ${ }^{13,15}$ This acute decompensation experienced by infants post ligation is of utmost importance, for it may place them at higher likelihood for poor long-term outcomes. Kabra et al. ${ }^{16}$ found infants with PDA's closed surgically to be more likely to develop bronchopulmonary dysplasia with the need for supplemental oxygen, severe retinopathy of prematurity and cognitive delay. Doyle et al. ${ }^{17}$ showed that the association between surgery and subsequent neurosensory impairment may be due to perioperative cardiorespiratory instability. The present study intended to investigate the immediate outcome only and as such the comment on long-term outcome is left pending until the follow up data are available.

But why some infants are able to tolerate PDA ligation without severe hypotension and respiratory failure and some are not, is still a myth. Relative adrenal insufficiency may have a role in the way infants vary in their responses to stress. A subset of infants may have an inadequate cortisol response during acute illness that results in changes in vasomotor tone, hypotension and increased dependence on vasopressor support. ${ }^{13,18}$ Satpute and colleagues ${ }^{14}$ postulated that relative adrenal insufficiency may have a role in the postoperative decompensation of some premature infants and, providing $\mathrm{HC}$ before the stressful event may aid the infants in inducing an appropriate response and possibly prevent poor long-term outcomes. Identifying infants with relative adrenal insufficiency is difficult; measuring cortisol levels may be useful, however, studies have shown that low cortisol levels are not helpful in defining a population who would benefit from HC therapy. ${ }^{11,18,19}$ Interestingly, those infants who were not pretreated with prophylactic stress $\mathrm{HC}$ but subsequently required $\mathrm{HC}$ for pressor-resistant hypotension were not clinically different from the rest of the same group further indicating the challenge of identifying the infants who will actually be benefited from prophylactic stress HC.

The concept of using prophylactic $\mathrm{HC}$ to prevent cardiopulmonary instability following PDA ligation emanates from the use of $\mathrm{HC}$ for treatment of shock in preterm infants. Administering physiological doses of $\mathrm{HC}$ to infants with refractory hypotension has shown to produce favorable cardiovascular outcome. ${ }^{12}$ Noori et al $^{13}$ has demonstrated $\mathrm{HC}$ to improve blood pressure without compromising cardiac function, systemic perfusion or endorgan blood flow in human neonates. The impact of $\mathrm{HC}$ on improved blood pressure in the present study may be explained by these physiological responses to HC. Thus, the decreased need for vasopressor therapy postoperatively in the HC-treated infant may not be entirely related to relative adrenal insufficiency, but rather the response to the therapy.

Overall, these were the plausible explanation of the effects of stress dose $\mathrm{HC}$ prophylaxis in infants undergoing surgical ligation of PDA. However, like any other scientific studies the present study is 
not without limitations. The study was done to examine the postoperative hospital outcome which alone cannot justify the overall outcome unless the data of long-term consequence of these infants are available. Besides, the small sample size did not allow us to go for regression analysis to justify whether the stress dose HC prophylaxis could independently predict the outcome what we have found in the present study. We postulate prophylactic stress $\mathrm{HC}$ may have prevented the preterm infants in our study from worse postoperative cardiorespiratory outcomes, but this requires validation by further large-scale study before generalization.

\section{REFERENCES}

1. Forsey JT, Elmasry OA, Martin RP. Patent arterial duct. Orphanet J Rare Dis 2009;4:17-26.

2. Lee GY, Sohn YB, Kim MJ, Jeon GW, Shim JW, Chang YS et al. Outcome following surgical closure of patent ductusarteriosus in very low birth weight infants in neonatal intensive care unit. Yonsei Med J 2008;49(2):265-71.

3. Raval MV, Laughon MM, Bose CL, Phillips JD. Patent ductusarteriosus ligation in premature infants: who really benefits, and at what cost? J Pediatr Surg 2007;42(1):69-75.

4. Sellmer A, Bjerre JV, Schmidt MR, McNamara PJ, Hjortdal VE, Høst $B$, Bech BH, Henriksen TB. Morbidity and mortality in preterm neonates with patent ductus arteriosus on day 3. Arch Dis Child Fetal Neonatal Ed. 2013;98(6):F505-10. doi: 10.1136/archdischild-2013-303816. Epub 2013 Jul 26.

5. Naik-Mathuria B, Chang S, Fitch ME, Westhoff J, Brandt $M L$, Ayres NA et al. Patent ductusarteriosus ligation in neonates: preoperative predictors of poor postoperative outcomes. J Pediatr Surg 2008;43(6):1100-05.

6. Jhaveri N, Moon-Grady A, Clyman RI. Early surgical ligation versus a conservative approach for management of patent ductus arteriosus that fails to close after indomethacin treatment. J Pediatr 2010;157:381-7.

7. Sehgal A, Coombs P, Tan K, McNamara PJ. Spectral Doppler waveforms in systemic arteries and physiological significance of a patent ductus arteriosus. J Perinatol 2011;31:150-6.

8. Teixeira LS, Shivananda SP, Stephens D, Van Arsdell G, McNamara PJ. Postoperative cardiorespiratory instability following ligation of the preterm ductusarteriosus is related to early need for intervention. J Perinatol 2008;28(12):803-10.
9. Harting MT, Blakely ML, Cox Jr CS, Lantin-Hermoso $\mathrm{R}$, Andrassy RJ, Lally KP. Acute hemodynamic decompensation following patent ductusarteriosus ligation in premature infants. J Invest Surg 2008;21(3):133-38.

10. Ng PC, Lee $\mathrm{CH}$, Bnur FL, Chan $\mathrm{IH}$, Lee AW, Wong $\mathrm{E}$ et al. A double-blind, randomized, controlled study of a "stress dose" of hydrocortisone for rescue treatment of refractory hypotension in preterm infants. Pediatrics 2006;117(2):367-75.

11. Baker CF, Barks JD, Engmann C, Vazquez DM, Neal Jr $\mathrm{CR}$, Schumacher RE et al. Hydrocortisone administration for the treatment of refractory hypotension in critically ill newborns. J Perinatol 2008;28(6):412-19.

12. Seri I, Tan R, Evans J. Cardiovascular effects of hydrocortisone in preterm infants with pressor-resistant hypotension. Pediatrics 2001;107(5):1070-74.

13. Noori S. Pros and cons of patent ductus arteriosus ligation: hemodynamic changes and other morbidities after patent ductus arteriosus ligation. Semin Perinatol 2012;36(2):139-45.

14. Satpute MD, Donohue PK, Vricella L, Aucott SW. Cardiovascular instability after patent ductus arteriosus ligation in preterm infants: the role of hydrocortisone. Journal of Perinatology 2011:1-5.

15. Teixeira LS, Shivananda SP, Stephens D, Van Arsdell G, McNamara PJ. Postoperative cardiorespiratory instability following ligation of the preterm ductus arteriosus is related to early need for intervention. $J$ Perinatol 2008;28(12):803-10.

16. Kabra NS, Schmidt B, Roberts RS, Doyle LW, Papile L, Fanaroff A. Neurosensory impairment after surgical closure of patent ductus arteriosus in extremely low birth weight infants: results from the Trial of Indomethacin Prophylaxis in Preterms. J Pediatr 2007;150(3):229-34.

17. Doyle LW. Outcome at 5 years of age of children 23 to 27 weeks' gestation: refining the prognosis. Pediatrics 2001;108(1):134-41.

18. Aucott SW, Watterberg KL, Shaffer ML, Donohue PK. Do cortisol concentrations predict short-term outcomes in extremely low birth weight infants? Pediatrics $2008 ; 122(4): 775-81$.

19. Masumoto K, Kusuda S, Aoyagi H, Tamura $\mathrm{Y}$, Obonai T, Yamasaki $C$ et al. Comparison of serum cortisol concentrations in preterm infants with or without late-onset circulatory collapse due to adrenal insufficiency of prematurity. Pediatr Res 2008;63(6):686-90. 